\title{
Translational mechanisms in business model design: introducing the continuous validation framework
}

\author{
Leonardo Corbo \\ Department of Management, University of Bologna, Bologna, Italy and \\ Research Centre in Management and Economics (CEGE), \\ Universidade Catolica Portuguesa Catolica Porto Business School, Porto, Portugal \\ Shadi Mahassel \\ SURFnCODE, Matosinhos, Portugal, and \\ Alberto Ferraris \\ Department of Management, \\ Universita Degli Studi Di Torino Dipartimento Di Management, Torino, Italy and \\ Graduate School of Economics and Management, \\ Ural'Skii Federal'nyi Universitet Imeni Pervogo Prezidenta Rossii B N El'tsina, \\ Ekaterinburg, Russian Federation
}

\begin{abstract}
Purpose - This paper aims at proposing knowledge translation as an element of business model design that can support entrepreneurs in achieving alignment and collaboration between entrepreneurial teams and external stakeholders.

Design/methodology/approach - The conceptual model presented in the paper is developed from the literature review and draws mainly on two streams of work as follows: first, the contributions related to the lean start-up methodology initially developed by Blank and Ries and second, the work of Osterwalder and Pigneur on business models and its subsequent developments. In addition, we draw on key insights from the entrepreneurship and organizational learning literature, such as discovery-driven planning and disciplined entrepreneurship.

Findings - The continuous validation framework (CVF) is introduced, posing the attention on underlining knowledge-translation mechanisms to decode complex concepts related to new venture creation.

Originality/value - The authors propose a new framework (the CVF) as an effective translational tool because it is a visual diagram that allows entrepreneurs to translate complex and technical ideas into a format that is more understandable for external audiences. Additionally, for each step of the CVF, specific translational mechanisms are defined and discussed, as each stage of the CVF presents specific translational challenges that result in outcomes that differ from stage to stage.
\end{abstract}

Keywords Business model, Business model design, Translational mechanisms, Knowledge-based view, Knowledge translation, Start-ups

Paper type Research paper

\section{Introduction}

Business models describe the design or architecture of the value creation, delivery and capture mechanisms a firm employs (Teece, 2010) and have become a useful tool to understand how firms can achieve superior returns and competitive advantage (e.g. Osterwalder and Pigneur, 2010).

(C) Leonardo Corbo, Shadi Mahassel and Alberto Ferraris. Published by Emerald Publishing Limited. This article is published under the Creative Commons Attribution (CC BY 4.0) licence. Anyone may reproduce, distribute, translate and create derivative works of this article (for both commercial and non-commercial purposes), subject to full attribution to the original publication and authors. The full terms of this licence may be seen at http://creativecommons.org/licences/by/4.0/legalcode
Continuous

validation

framework

Received 26 October 2019

Revised 15 February 2020 4 April 2020

Accepted 8 April 2020 
Previous research on business models has focused mainly on value creation through specific business model configurations (Chesbrough and Rosenbloom, 2002; Kim and Min, 2015). Yet, less is known about the process of designing winning business models (i.e. getting to a specific business model configuration) even though the design of a business model is a key decision for both entrepreneurs developing a new model and general managers in charge of rethinking their existing models (Zott and Amit, 2010). This lack of attention at the design component of business models is particularly surprising in the field of entrepreneurship because business models may represent a form of entrepreneurial opportunity creation (Markides, 2008) stimulated by the existence of market imperfections (Cohen and Winn, 2007).

As a consequence, a mismatch between the goals and the vision pursued by entrepreneurial teams and the requirements of external actors can arise, frequently leading to startups' high failure rates. Conflicts are well known in this context, such as when entrepreneurs and early investors have diverging views on how to allocate financial resources or when heterogeneity within the founding team results in conflicting needs and priorities, disagreements on crucial decisions and misalignment in terms of which kind of value to create (e.g. Turcan, 2008).

To address this puzzle, previous lines of enquiry have highlighted that in the presence of different objectives, goals and backgrounds there is a need for translators or translation mechanisms, that can help define a common platform of communication and knowledge sharing and transfer among diverse individuals (Chiesa and Piccaluga, 1998; Simeone et al., 2018). Building on these intuitions, we first propose that knowledge-translation mechanisms are an integral component of business model design which requires the development of a common "language", concrete tools and a framework (Zott and Amit, 2010) understandable by multiple audiences (e.g. academics, entrepreneurs, managers and investors). Then, we put forward the idea that translational mechanisms support entrepreneurs to achieve learning through a process of trial and error that relies less on intuition and more on experimentation, prototyping and hypothesis testing.

Moreover, business model design emerges as a powerful instrument for early-stage ventures because entrepreneurs can use business models as a tool for the abstraction of the whole company (Wirtz et al., 2016). In fact, abstractions are also useful in translating complex and tacit knowledge into a language that is easier to understand for knowledge recipients that reside outside of the firm. However, while translation as a mechanism to support organizational learning in more mature settings has been studied (Savory, 2006; Simeone et al., 2017a), there is still limited research about how to support the process of learning of entrepreneurial teams through translation.

In an attempt to cover these gaps, the paper proposes a conceptualization of knowledge translation as an integral element of business model design to achieve internal as well as external alignment and collaboration with external stakeholders. Our novel framework aims at guiding entrepreneurs through a process of continuous iteration and validation of ideas, ultimately leading to entrepreneurial learning. Therefore, this paper attempts to address the following question: Can knowledge-translation mechanisms in the design of business models be considered as an effective means to achieve alignment between the needs and interests of entrepreneurial teams and the demands of external stakeholders? To address this question, the paper will first review the theoretical and empirical contributions related to business model design and experimentation and highlight the relevance of knowledge translation in the design of business models. Next, building on the recent Bortolini et al. (2018) review, the main existing frameworks for business model design will be presented, namely the business model canvas (BMC) (Osterwalder and Pigneur, 2010) and the lean start-up (LS) methodology (Blank, 2003; Ries, 2011). Finally, we propose a new conceptual model, the continuous validation framework $(\mathrm{CVF})$ that is developed from the literature review and draws on two streams of work as follows: first, the contributions related to the LS methodology initially developed by Blank (2003) and Ries (2011); second, the work of Osterwalder and Pigneur 
(2010) on business models and its subsequent developments. In addition, we draw on key insights from the entrepreneurship and organizational learning literature, such as discoverydriven planning and disciplined entrepreneurship.

This paper contributes to the entrepreneurship and innovation literature in three ways. First, we contribute to the growing literature on business model design (Zott and Amit, 2010; Rask and Günzel-Jensen, 2019) by placing emphasis on design as an important antecedent of developing effective business models. Second, we put forward the idea that business model design encompasses useful mechanisms for entrepreneurs wishing to translate complex concepts related to their start-up (e.g. product, value offer), often embedded in the tacit knowledge repository of the entrepreneurial team, into a language that is more easily transferable to external audiences. By so doing, we extend the emerging literature on knowledge translation in entrepreneurial settings (Secundo et al., 2019) by exploring the role of business model design as a means to acquire and transfer knowledge within entrepreneurial projects. Finally, we introduce a new framework - the CVF - which integrates and complements existing frameworks on business model design by emphasizing extensive idea validation and iteration, ultimately increasing the probability of reaching alignment and collaboration between different stakeholders.

\section{A knowledge-based perspective of business model design in entrepreneurial settings}

Over time, the "business model" concept has attracted significant attention because it suggests a path through which businesses are conceived, created and executed (e.g. Osterwalder and Pigneur, 2010). Parallel to the development of business model studies in mature settings (Chesbrough and Rosenbloom, 2002; Corbo, 2017), there has been a growing interest in business models in entrepreneurial settings (Presenza and Petruzzelli, 2019). This distinction is important as, in the context of start-ups, business models cannot be fully anticipated in advance but rather must be learned over time (McGrath, 2010). As such, business models emphasize the central role of experimentation for entrepreneurs to rapidly test the market, validate or reject key assumptions and learn through experience which in turn leads to refinement and improvement of a venture's business model. The initial stages often require experimenting with alternative business model configurations (Chesbrough, 2010) before identifying the business model matching demand requirements. This stage has been defined as the exploration phase, and it is characterized by trial-and-error learning (Sosna et al., 2010), resulting in the accumulation of relevant experience and knowledge.

To explain the process of how experience is transformed into knowledge, a widely used theoretical approach in entrepreneurial research is Kolb's (1984) experiential learning theory which portrayed the process of constructing knowledge as an idealized learning cycle. Kolb's experiential learning cycle indicates how concrete experience is transformed into abstract conceptualization through reflective observation, which in turn results in the next occurrence of concrete experience through active experimentation (Kolb, 1984). While interesting, recent contributions have pointed out that how the full experiential cycle occuring in entrepreneurial firms needs further research (Wang and Chugh, 2014).

With this relevant gap in mind, the next paragraph focuses on how experimentation in the process of designing a business model can serve as a mechanism by which entrepreneurial learning occurs. Because learning is often the result of knowledge transfer and in entrepreneurial settings this might entail that knowledge is transferred across diverse actors and contexts (e.g. previous knowledge accumulated by one cofounder transferred into the new venture), knowledge needs to be translated for it to be interesting and relevant (Graham et al., 2006). Translating knowledge involves processing new knowledge and interpreting it to the needs and interests of the new venture for it to be transformed into forms that are suitable for the context in which the new venture is embedded (Simeone et al., 2017a). Accordingly, this paper focuses on knowledge translation processes in entrepreneurial ventures and describes
Continuous validation framework 
the translational mechanisms at play when designing business models that can help entrepreneurial teams exchange knowledge with external audiences.

\section{Knowledge-translation mechanisms as an integral component of business model design}

Recent studies have started to increasingly consider design (i.e. making sense of things) (e.g. Krippendorff, 2006) as a translational mechanism to align the needs and interests of various stakeholders (Simeone et al., 2017b; Secundo et al., 2019). Broadly defined, design encompasses a set of practices and methods, including user research and user testing, rapid and frequent prototyping and visualization techniques, which also mark a distinctive way of thinking, approaching and solving problems (Buchanan, 2004). This symbolic, meaning-making practice of design (Krippendorff, 1989) fits with the idea of design as a "translation of ideas" (e.g. Do et al., 2000). Translation has been described as a process where, for example, a sketch or a visual diagram translates some complex, technical ideas developed by some researchers in nanotechnologies into a format that is easier to understand for nonprofessional, nonacademic audiences (Simeone et al., 2017b). Similarly, entrepreneurs often rely on sketches, diagrams and other visual interfaces to translate complex concepts and entrepreneurial ideas into formats that are faster to understand for external audiences such as prospective customers and potential investors.

Design has often been utilized in studies related to business models. The relevance of translational mechanisms within the design of business models has been highlighted in one of the early studies on business models (Osterwalder, 2004: 7, words italicized for emphasis): "The reasoning behind business model research is not the understanding of a phenomenon, rather it is a problem-solution finding approach ... It means designing and building a model that makes it possible to represent the business model of a firm". In one of its original conceptualizations, a business model has been defined as a "blueprint" for how to run a business (Osterwalder et al., 2005). This correctly expresses the notion that business models are an abstraction of the principles supporting the development of the core repeated standard processes necessary for a firm to perform its business (Cavalcante et al., 2011). Abstractions are also useful in translating complex and tacit knowledge into a language that is easier to understand for knowledge recipients that reside outside of the firm. In the context of earlystage ventures, for instance, it can take the form of an entrepreneur pitching his/her venture idea to potential investors by illustrating the key business model components through visual interfaces and diagrams. As such, abstract representations of business models through canvases, templates and frameworks elucidate how a firm is linked to external stakeholders, acting as a bridge to transfer knowledge from one end to the other.

This boundary-spanning view of business models treats design as a central task for entrepreneurs. Ignoring the need to align the business model with the requirements of the external environment can lead to company failure (Hargadon and Douglas, 2001). However, while the value creation aspect of business model design has been analyzed in greater detail with several researchers studying the business model design-performance relationship (Zott and Amit, 2008; Pati et al., 2018), none of these studies addresses the relationship between business model design, translation and entrepreneurship explicitly. In this article, we aim to investigate if and how translational mechanisms facilitate entrepreneurs' experimentation and learning when designing their venture's business model and ultimately help them to achieve alignment between their interests and those of external stakeholders.

\section{Emerging frameworks on business model design}

A growing stream in entrepreneurship research argues that new ventures design and redesign their business model through a process of experimentation and learning (e.g. 
Picken, 2017). Accordingly, several frameworks have emerged to help entrepreneurs visualize and test their ideas with formats that are often utilized by both academics and practitioners. While deeply rooted in practice, in recent years, scholars have fruitfully anchored these frameworks to the academic managerial literature. Some of these contributions include disciplined entrepreneurship (Sull, 2004), discovery-driven planning (McGrath, 2010) and organizational learning (Levitt and March, 1988). In this paragraph, we provide a brief overview of the frameworks that have become a core reference for entrepreneurs and researchers in the field of entrepreneurship.

Building on the work of Blank (2003), who originally articulated the notion of LS, Ries (2011) further popularized the LS concept. LS is an approach for launching businesses and products that relies on validated learning, scientific experimentation and iterative product releases to shorten product development cycles, measure progress and gain valuable customer feedback. The ultimate goal of the LS approach is to help entrepreneurs design products or services to meet the demands of their customer base without requiring large amounts of initial funding or expensive product launches (Ries, 2011). The LS methodology draws heavily on lean manufacturing, a process that emphasizes speed of innovation through rapid iterations and reduction of waste through small batch production and learning from short cycles (Shah and Ward, 2003). Similarly, the LS methodology seeks to optimize the use of scarce resources by using smaller and faster iterations for testing the entrepreneur's assumptions continuously to achieve a product that customers will buy (i.e. product-market fit). To test these assumptions, a minimum viable product (MVP) is created. An MVP is the version of the product that has the smallest set of features, is built with the shortest amount of time and resources but is enough to provide the entrepreneur with the information to validate or reject the initial assumptions (Ries, 2009). If the hypotheses are confirmed, then productmarket fit is achieved, while if hypotheses are rejected, it is suggested to rerun MVP tests until product-market fit is achieved (Eisenmann et al., 2012). This process of experimentation based on the analysis of solid empirical data obtained from real customers and defined as the build-measure-learn (BML) cycle results in validated learning (Ries, 2011).

One of the fundamental principles of the lean methodology, as initially conceived, is that early-stage entrepreneurs should avoid writing lengthy business plans and instead sketch their hypotheses and summarize them in a framework defined as the BMC, i.e. a diagram of how a company creates value for itself and its customers (Ries, 2011). In perhaps one of the most influential doctoral outputs produced in the last two decades in the field of management, Osterwalder (2004) proposed a systematization of the business model concept in the BMC, later refined by Osterwalder and Pigneur (2010). These authors describe the business model through nine basic building blocks that show the logic of how a company intends to create, deliver and capture value. These nine blocks cover the four main areas of a business as follows: (1) customers comprising the building blocks "customer segments", "channels" and "customer relationships", (2) offer comprising the building block "value proposition", (3) infrastructure which includes "key resources", "key activities" and "key partnerships" and (4) financial viability comprising the building blocks "cost structure" and "revenue streams".

\section{A new conceptual model: the continuous validation framework}

The CVF is conceived to help entrepreneurial teams validate products, and hence business models, in rapid iterations, placing the customer at the core of the product development process. This allows teams to identify problems worth solving and test solutions rapidly. Compared to the frameworks summarized in the previous paragraph, the CVF presents several elements of differentiation and novelty.

First, while there is consensus about the usefulness of sketching assumptions and hypotheses into a single-page format such as the BMC (Blank, 2013), it has been noted that
Continuous validation framework 
some of its elements appear as "too general" (Maurya, 2012: 40) and partially mismatched with the priorities emerging during the early stages of a start-up. For example, the BMC lacks some of the critical elements of the business model design for start-ups, such as the articulation of problem and solution. Moreover, it is based on the premise that the entrepreneur somehow already knows the venture's value proposition. On the contrary, in the $\mathrm{CVF}$, the value proposition is developed only after reaching the problem-solution fit. Finally, by requiring entrepreneurs to list their "key activities" before testing their solution, the BMC is silent on the validation and development aspects of a product, which can be found on the left side of the CVF. To that respect, the CVF can complement the BMC by allowing entrepreneurs to (1) develop a value proposition after reaching a problem-solution fit and (2) build and test their product in the CVF while sketching hypotheses on their profit formula in the BMC.

Process-wise, the CVF finds common ground with the LS methodology that is based on continuous improvement cycles. For example, quick deliveries, fast feedback integration and business agility are common points between the two approaches. Yet, the CVF differs from the BML diagram developed by Ries (2011) in one fundamental aspect. The BML feedback loop starts with the "build" stage, which entails building a minimum viable product, then moves to measure how customers react to and interact with the product, which allows entrepreneurs to learn. The CVF, instead, puts the MVP as a final step of its loop preceded by the need for entrepreneurs to test whether they have identified a problem worth solving, i.e. a problem-solution fit. By so doing, the CVF complements the BML and derisks product development through extensive validation that ensures start-up founders do not stick necessarily to their original idea but instead embrace the one that is more likely to lead them to a problem-solution fit before building an MVP. Figure 1 summarizes how the CVF complements and integrates the BMC and the BML diagram.

The CVF is a six-step process model divided into four stages each of which addresses a specific question as follows: what is the problem worth solving (discover), what is the value proposition (define), what is the product roadmap (deliver) and whether entrepreneurs have achieved product-market fit (measure) (see Figure 2).

The starting point of the framework is the discovery stage, where the main goal is to find a problem that impacts a broad audience. Some of the questions that entrepreneurs need to answer at this stage include the identification of the problem's dimension (how big is the problem?), the frequency by which the problem impacts a person's life (is it the most important problem?), the ways in which people address the problem and the opportunity that emerges by tackling this problem [1]. While previous studies have suggested that entrepreneurs can recognize opportunities by not actively seeking for them (Ardichvili et al., 2003), our framework emphasizes the need for an active search for opportunities, particularly through the interaction with users impacted by the problem entrepreneurs are addressing. Access to appropriate information plays a crucial role in opportunity recognition (Shane, 2003) and helps entrepreneurs shape the solution. Besides the information available to entrepreneurs through their industry or market knowledge and the analysis of environmental contingencies, customer interviews represent a powerful tool to gather valuable information and understand whether entrepreneurs have reached a problemsolution fit (Maurya, 2012). Both problem and solution steps are conducted in an iterative fashion, and iterations can take place several times before identifying a problem worth solving (Blank, 2003).

Customer interviews performed in the first stage represent a translational mechanism as they are intended to help entrepreneurs translate abstract entrepreneurial ideas into problems and features that have a concrete impact on potential customers. The "problem" interviews help entrepreneurs learn about the relevance of the identified problem for potential customers and early adopters as well as how significant is the problem to customers using 


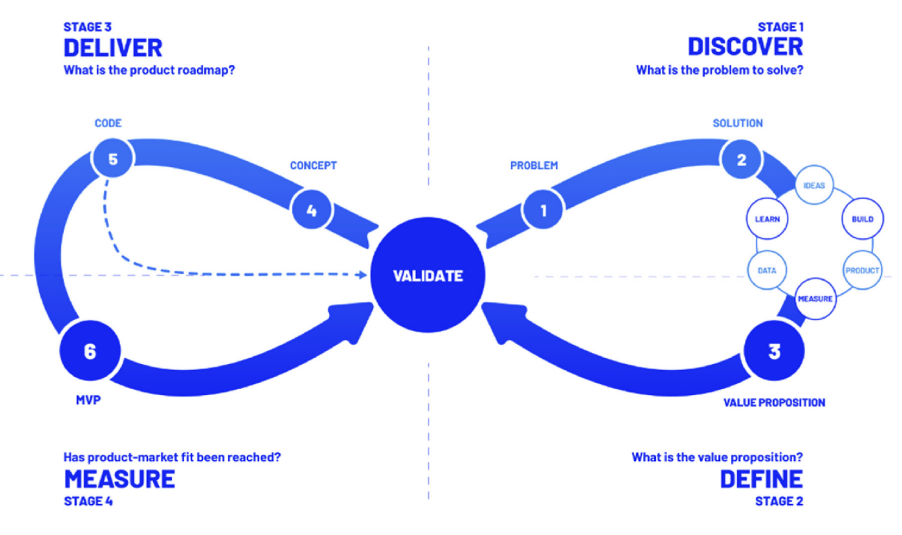

Continuous validation framework

2017

The Business Model Canvas

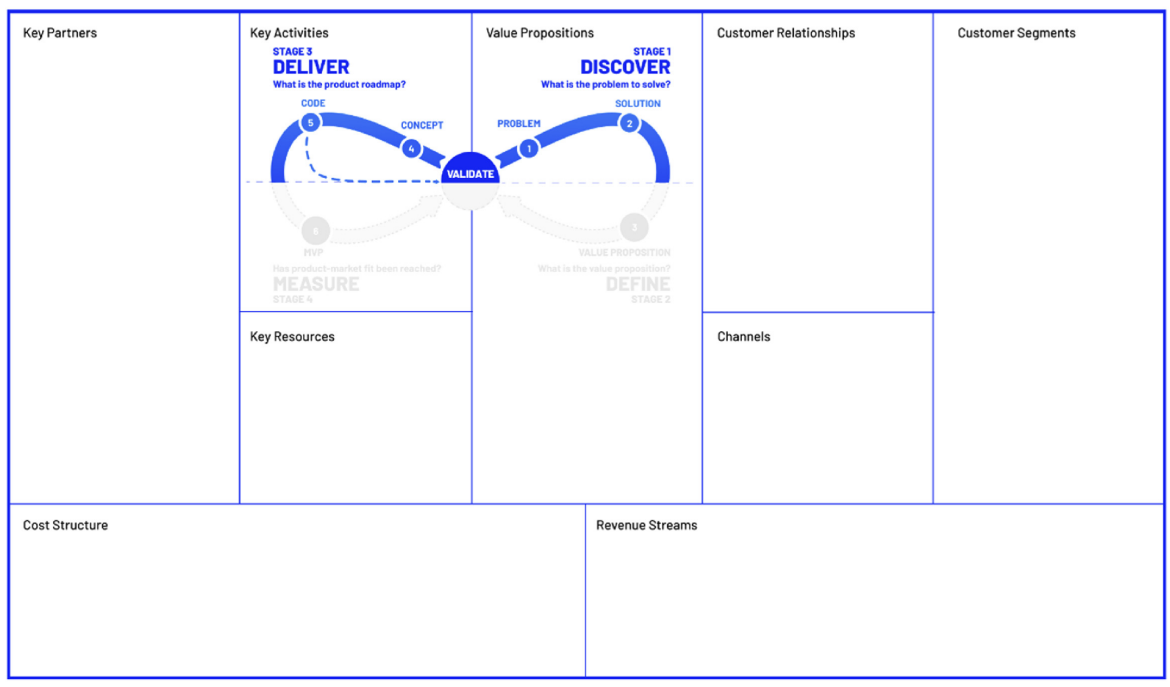

Figure 1. Integration between the CVF, the BML diagram and BMC

similar solutions. At this stage, interviews could be extended to get valuable feedback from other external actors, such as existing solution providers. Based on the information gathered through these interactions, entrepreneurs are able to redefine the problem and proceed to perform "solution" interviews, which allow eliminating unnecessary or flawed assumptions. An additional translational mechanism that can be used in this step consists of simplified versions of technological artifacts (Gherardi and Nicolini, 2000) that support entrepreneurs illustrating how they aim to solve a specific problem through visual elements.

In stage two, the focus is on developing the value proposition. Some of the challenges that entrepreneurs face at this stage include choosing one or more customer segments to address among the ones identified and developing initial metrics to track user interaction with the solution as well as defining the company's business model. With respect to business model development, entrepreneurs should identify customers' willingness to pay (WTP) and go-tomarket (GTM) strategies. An additional challenge that entrepreneurs face at this stage is to convince an early-stage investor (e.g. a business angel) to provide a small amount of funding. 
$\mathrm{MD}$

58,9

2018
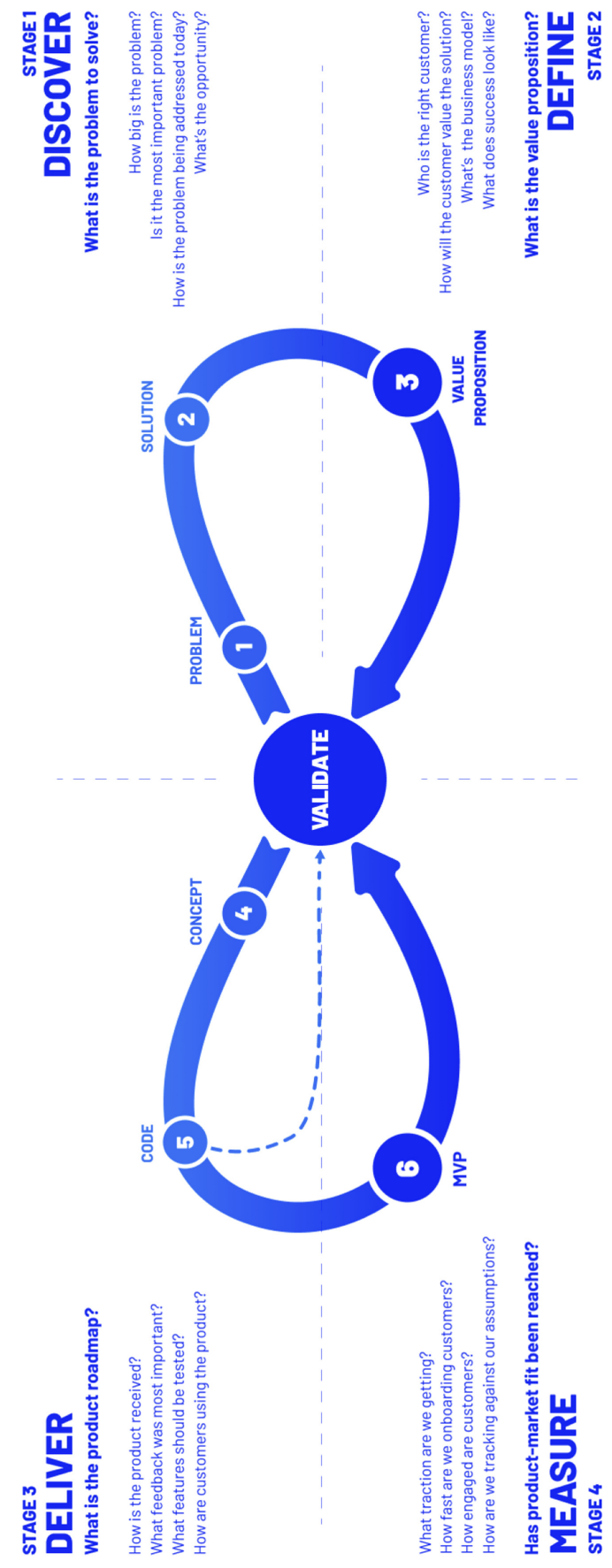

Figure 2.

The CVF 
To facilitate interaction with external actors such as early-stage investors and potential partners, the creation of a competitors' matrix (indicating core features of competitors' product offering, reputation scores and pricing) benchmarking the start-up's value proposition against competitors represents a useful translational mechanism. This stage is also particularly relevant for entrepreneurs as it requires them to translate the information and knowledge obtained through customer interviews into an "embryonic" version of the product that will be used to test the hypotheses formulated in the discovery stage. Therefore, while in the "discovery" stage the goal is to have a broad set of assumptions, possibly without ruling out any of them, in the "define" stage, the goal is to create a list of priorities based on what entrepreneurs have learned previously. Such priorities include defining the value proposition, the main customer segment(s) to address and the revenue and cost models (Teece, 2010).

The transition from the "define" to the "deliver" stage entails that the initial set of ideas and hypotheses are used to create artifacts that allow moving from abstraction to visual representations. These artifacts can be as simple as wireframes that test user experience (UX), a data point if the product is software or take the form of a 3D-printed device if the product is hardware and can be used as knowledge-translation mechanisms in the proof of concept step because they force entrepreneurs to translate their abstract ideas into a language understandable by external audiences. The third stage is, therefore, devoted to learning how to design the best solution for addressing the market need(s) identified previously. This stage requires entrepreneurs to validate the use of the product features specified for the MVP step and to identify and further test how customers use the product. By so doing, entrepreneurs can select the most important features of their product, understand how users interact with the product and what is causing them to churn. In the proof of concept step, new functionalities can be added and previous features revised, as the proof of concept is tested and iterated through feedback from early users. Depending on the amount and quality of feedback received, the proof of concept can evolve into a functional prototype, which is a first attempt at making a working model that might find concrete usage on the market (Singaram and Jain, 2018).

The advantage of going through stages one to three is the opportunity to iterate and refine assumptions and hypotheses multiple times and get closer to the most viable solution faster and at a lower cost, instead of coding "blindly" before obtaining insights on prospective customers. The passage from proof of concept to programming (coding) in the CVF implies taking a solid step toward building a more complete product, which helps the entrepreneurial team to further translate its vision into testable hypotheses about its solution. Therefore, in the "deliver" stage, validation is related to multiple aspects, including technology, usability and marketability of the product in real-life scenarios.

The fourth and last stage, "measure", is where the entrepreneurial team validates and tests once more the previously formulated hypotheses by iterating an MVP. Because the goal of such an exercise is to confirm or falsify entrepreneurs' assumptions, the MVP is considered as an experiment (Contigiani and Levinthal, 2019). Moreover, an MVP can be deployed as a translational mechanism to measure the reaction of early adopters and collect valuable information to engage them further in the development process, increasing the chances of achieving alignment between the entrepreneurs' objectives and customer demand. As such, an MVP should be considered as an ongoing process and not as a milestone. This is because entrepreneurs typically employ more than one MVP, and with each MVP, they learn about customer requirements, which helps to improve the product instead of investing too many resources upfront in building a product surrounded by high uncertainty on whether or not it will meet consumer demand.

In sum, the CVF as a whole can be considered as a translational mechanism because it is a visual diagram that allows entrepreneurs to translate some complex, technical ideas into a
Continuous validation framework 
format that is more understandable for external audiences. However, as each stage of the CVF presents specific translational challenges, entrepreneurs can use specific translational mechanisms to interact with external actors, resulting in outcomes that differ from stage to stage (see Table 1).

\section{Discussion and conclusion}

6.1 Synthesis of major findings

This paper sets out to investigate knowledge-translation mechanisms as an integral component of business models in the context of entrepreneurial projects. In particular, the paper introduced a novel model, the CVF, that helps entrepreneurial teams collaboratively interact with external stakeholders through constant validation of the team's hypotheses from users, customers, investors and vendors.

While the business model concept is universally applicable to any company regardless of its age, designing business models for nascent vs mature firms presents different challenges as business models are adjusted in parallel to a firm's life cycle evolution (Corbo et al., 2018; Landoni et al., 2019). Business model design is a fundamental task for entrepreneurs developing a new business model (Zott and Amit, 2010), even most importantly in new settings such as smart city projects (Bresciani et al., 2018; Ardito et al., 2019). As business models represent an abstraction of the whole company (Wirtz et al., 2016), they allow translating complex and tacit knowledge into a language that is easier to understand for knowledge recipients that reside outside of the firm. Therefore, business model design emerges as a powerful knowledge-translation mechanism for early-stage ventures.

While research provides a clear understanding of how translation mechanisms support organizational learning in mature settings (Savory, 2006; Simeone et al., 2017a), we lack a nuanced understanding of knowledge-translation mechanisms to support the development of entrepreneurial projects and, in particular, the role of knowledge translation in the design of business models. In an attempt to cover this gap, this paper provided insights on how translational mechanisms support the process of designing a business model and, consequently, achieving alignment between the requirements of the external audiences and the goals of the entrepreneurial team. The paper outlined several translational mechanisms through which a business model design supports knowledge exchange between entrepreneurial teams and external audiences. These include the following: (1) discovering a problem to solve by interacting with potential customers, (2) receiving valuable feedback from users through their interaction with early versions of the product and (3) reaching alignment between entrepreneurial team members and external stakeholders. These translational mechanisms may be a useful way to test hypotheses and assumptions about the product and align the different needs and interests of the stakeholders involved.

\subsection{Implications for theory}

Our paper shows some interesting implications for theory. First, we add to the growing literature on business models (e.g. Chesbrough, 2010; Teece, 2010) by highlighting the importance of design as a key antecedent of developing effective business models. Second, we suggest that knowledge-translation mechanisms are an integral element of business model design to decode complex concepts related to new venture creation (e.g. product, value offer), which are often embedded in the tacit knowledge repository of the entrepreneurial team and make it more understandable to external stakeholders. By so doing, we extend the emerging literature on knowledge translation in entrepreneurial settings (e.g. Secundo et al., 2019) through a focus on the role of business model design as a tool to share knowledge within and 


\begin{tabular}{|c|c|c|c|c|c|}
\hline Stage & Step & Audience & Translation mechanisms & Outcome & Continuous \\
\hline \multirow[t]{2}{*}{ Discover } & \multirow[t]{2}{*}{ Problem } & \multirow[t]{2}{*}{$\begin{array}{l}\text { Potential customers; } \\
\text { early adopters; early- } \\
\text { stage investors and } \\
\text { existing solution } \\
\text { providers }\end{array}$} & \multirow[t]{2}{*}{$\begin{array}{l}\text { Problematization through } \\
\text { customer interviews (Blank, } \\
\text { 2003; Maurya, 2012) }\end{array}$} & \multirow{2}{*}{$\begin{array}{l}\text { Learning about how } \\
\text { relevant the problem is for } \\
\text { potential customers, how } \\
\text { important the problem is to } \\
\text { the existing customers of } \\
\text { similar solutions, what } \\
\text { other related important } \\
\text { problems do the customers } \\
\text { have and how the problem } \\
\text { is addressed today. } \\
\text { Redefinition of the problem } \\
\text { based on feedback from } \\
\text { interviewees }\end{array}$} & framework \\
\hline & & & & & \\
\hline Discover & Solution & $\begin{array}{l}\text { Potential customers; } \\
\text { early adopters; } \\
\text { potential partners } \\
\text { and vendors }\end{array}$ & $\begin{array}{l}\text { Customer interviews to } \\
\text { identify existing solutions } \\
\text { and their shortcomings } \\
\text { (Maurya, 2012) and } \\
\text { technological artifacts } \\
\text { (Gherardi and Nicolini, 2000) } \\
\text { such as sketches and } \\
\text { templates }\end{array}$ & $\begin{array}{l}\text { Customer interviews allow } \\
\text { to eliminate unnecessary or } \\
\text { flawed assumptions about } \\
\text { customers' desired features } \\
\text { of the product, as well as to } \\
\text { further explore in more } \\
\text { detail the solution } \\
\text { structure, architecture, } \\
\text { flow, etc. Technological } \\
\text { artifacts allow } \\
\text { entrepreneurs to illustrate } \\
\text { through the aid of visual } \\
\text { elements how they intend } \\
\text { to solve one or more } \\
\text { problems }\end{array}$ & \\
\hline Define & Product & $\begin{array}{l}\text { Potential customers; } \\
\text { early adopters; } \\
\text { potential partners } \\
\text { and vendors }\end{array}$ & $\begin{array}{l}\text { Research potential } \\
\text { competitors via archival } \\
\text { resources (i.e., desk research). } \\
\text { Examine competitors' } \\
\text { reputation, products, pricing } \\
\text { (Osterwalder and Pigneur, } \\
\text { 2010; Rohan and Hornblower, } \\
\text { 2008) and create comparison } \\
\text { tables. Interview existing } \\
\text { solution providers. Search for } \\
\text { disruptive solutions }\end{array}$ & $\begin{array}{l}\text { Business model and go-to- } \\
\text { market definition. } \\
\text { Evaluation of potential } \\
\text { partners and vendors }\end{array}$ & \\
\hline Deliver & $\begin{array}{l}\text { Proof of } \\
\text { concept }\end{array}$ & $\begin{array}{l}\text { Potential customers; } \\
\text { early adopters and } \\
\text { potential early-stage } \\
\text { investors }\end{array}$ & $\begin{array}{l}\text { Technological artifacts } \\
\text { (Gherardi and Nicolini, 2000) } \\
\text { such as wireframes, 3D } \\
\text { models and mockups } \\
\text { (technology feasibility) }\end{array}$ & $\begin{array}{l}\text { The customer can see and } \\
\text { visualize the solution, } \\
\text { interact with it, provide } \\
\text { feedback and identify } \\
\text { issues }\end{array}$ & $\begin{array}{r}\text { Table 1. } \\
\text { Audience, translation } \\
\text { mechanisms and } \\
\text { outcomes by stage of }\end{array}$ \\
\hline & & & & (continued) & \\
\hline
\end{tabular}


$\mathrm{MD}$ 58,9

\begin{tabular}{|c|c|c|c|c|}
\hline Stage & Step & Audience & Translation mechanisms & Outcome \\
\hline Deliver & Code & $\begin{array}{l}\text { Potential customers; } \\
\text { early adopters }\end{array}$ & $\begin{array}{l}\text { Iterative versions (user } \\
\text { desirability) (Blank, 2003; } \\
\text { Ries, 2011) }\end{array}$ & $\begin{array}{l}\text { Introduce the most } \\
\text { important features in real } \\
\text { usage scenarios. Test how } \\
\text { customers value the } \\
\text { solution. Identify flawed } \\
\text { assumptions and reaffirm } \\
\text { prioritization of most } \\
\text { important features for } \\
\text { MVP }\end{array}$ \\
\hline Measure & MVP & $\begin{array}{l}\text { Potential customers; } \\
\text { early adopters and } \\
\text { paying customers }\end{array}$ & $\begin{array}{l}\text { Incremental version of the } \\
\text { product (Eisenmann } \text { et al., } \\
\text { 2012; Ries, 2011) }\end{array}$ & $\begin{array}{l}\text { Measure key performance } \\
\text { indicators through data } \\
\text { and metrics. Identify areas } \\
\text { for improvement. Identify } \\
\text { problematic areas. } \\
\text { Measure satisfaction and } \\
\text { loyalty (Net Promoter } \\
\text { Score) }\end{array}$ \\
\hline
\end{tabular}

Table 1.

across entrepreneurial projects. Third, we integrate previous studies on business model design (e.g. Zott and Amit, 2010; Rask and Günzel-Jensen, 2019) by introducing a novel framework that underlines extensively the role of idea validation and iteration to improve alignment and collaboration between different stakeholders. Extensive idea validation and iteration through the steps proposed in the CVF help address recent critiques of the LS methodology related, among others, to inadequate guidance about how to generate hypotheses for experimentation (Felin et al., 2019). In this regard, our paper offers a detailed step-by-step list of translation mechanisms that allow entrepreneurs to engage with customers, vendors and other stakeholders, helping them to better "understand the process of experimentation with novel and impactful business models" (Bocken and Snihur, 2019, p. 7).

\subsection{Implications for practice}

The advantage of the framework presented in this paper is that, unlike previous discussions of business model design which often remain abstract, the link between conceptual-level description and real-world applications is made more evident, allowing entrepreneurial teams to iterate hypotheses and assumptions several times to include the learning component throughout the process and not at the end of it. Entrepreneurial teams looking to utilize the CVF proposed in this study have the opportunity to translate the complexity and the length, typical of business plans, into something more intuitive to understand and decodify. Following is noted by Ann Miura-Ko, one of the most influential investors in Silicon Valley, highlighting the relevance of business models as a translation mechanism: “... it's the business model that matters, not the business plan [...]. And the reason why that's really important is that business models will enable you to understand exactly what your assumptions are". Therefore, we believe this paper offers a valuable contribution to the discourse on the challenges and opportunities related to knowledge translation in collaborative environments by offering a novel tool supporting knowledge translation in entrepreneurial settings.

This research also shows that the business model design can play an important role in the development of entrepreneurial projects and that translational mechanisms such as sketches, visualizations and prototypes can help entrepreneurial teams collaborate with external audiences. The framework we proposed can be a useful instrument for entrepreneurs to reflect on the problem(s) they wish to address through their products and can better inform 
the way entrepreneurs formulate their falsifiable hypotheses and design their preliminary business model.

We suggest that by applying the fundamental principles of the CVF, entrepreneurial teams may be able to measure feedback received from users qualitatively and quantitatively and iterate the discovery process as needed. With every iteration, the entrepreneurial team learns and improves its value offer. By so doing, the CVF may be of help in reducing the risk of innovation, saving time and money on the road to product-market fit and creating the foundation for the team's vision to match the requirements of the external environment.

\subsection{Limitations and future research}

As with other studies relying on a conceptual framework (e.g. Chapman et al., 2002), we do not have sufficient empirical scientific data on the efficacy of the new framework proposed even if, from a practical standpoint, several encouraging results have been pointed out. Building on this limitation, future studies could rely on testing the effectiveness of CVF through a single or multiple case study methodology producing comparative analyses. Moreover, in line with other frameworks related to business models such as the BMC or the lean canvas, the CVF introduced in this paper presents a sequence of steps or building blocks that might be followed in a progressive order. While the order conceived in such frameworks generally applies to the majority of empirical settings, there might be exceptions in some specific industries or sectors that could be fruitfully highlighted by future studies.

\section{Note}

1. We follow the definition of opportunity provided by Baron (2006: 107), who describes opportunity "as a perceived means of generating economic value (i.e. profit) that previously has not been exploited and is not currently being exploited by others".

\section{References}

Ardichvili, A., Cardozo, R. and Ray, S. (2003), "A theory of entrepreneurial opportunity identification and development", Journal of Business Venturing, Vol. 18 No. 1, pp. 105-123.

Ardito, L., Ferraris, A., Petruzzelli, A.M., Bresciani, S. and Del Giudice, M. (2019), "The role of universities in the knowledge management of smart city projects", Technological Forecasting and Social Change, Vol. 142, pp. 312-321.

Baron, R.A. (2006), "Opportunity recognition as pattern recognition: how entrepreneurs "connect the dots" to identify new business opportunities", Academy of Management Perspectives, Vol. 20 No. 1, pp. 104-119.

Blank, S. (2003), The Four Steps to the Epiphany: Successful Strategies for Products that Win, K\&S Ranch Press, Palo Alto, California, CA.

Blank, S. (2013), "Why the lean start-up changes everything”, Harvard Business Review, Vol. 91 No. 5, pp. 63-72.

Bocken, N. and Snihur, Y. (2019), "Lean startup and the business model: experimenting for novelty and impact", Long Range Planning, doi: 10.1016/j.lrp.2019.101953.

Bortolini, R.F., Nogueira Cortimiglia, M., Danilevicz, A.D.M.F. and Ghezzi, A. (2018), "Lean Startup: a comprehensive historical review", Management Decision, doi: 10.1108/MD-07-2017-0663.

Bresciani, S., Ferraris, A. and Del Giudice, M. (2018), "The management of organizational ambidexterity through alliances in a new context of analysis: internet of Things (IoT) smart city projects", Technological Forecasting and Social Change, Vol. 136, pp. 331-338.

Buchanan, R. (2004), "Management and design: interaction pathways in organizational life", in Boland, R.J. and Collopy, F. (Eds), Managing as Designing, Stanford University Press, Stanford, California, CA, pp. 54-63. 
Cavalcante, S., Kesting, P. and Ulhøi, J. (2011), "Business model dynamics and innovation: (re) establishing the missing linkages”, Management Decision, Vol. 49 No. 8, pp. 1327-1342.

Chapman, R.L., Soosay, C. and Kandampully, J. (2002), "Innovation in logistic services and the new business model: a conceptual framework", Managing Service Quality: International Journal, Vol. 12 No. 6, pp. 358-371.

Chesbrough, H. (2010), "Business model innovation: opportunities and barriers", Long Range Planning, Vol. 43 Nos 2-3, pp. 354-363.

Chesbrough, H. and Rosenbloom, R.S. (2002), "The role of the business model in capturing value from innovation: evidence from Xerox Corporation's technology spin-off companies", Industrial and Corporate Change, Vol. 11 No. 3, pp. 529-555.

Chiesa, V. and Piccaluga, A. (1998), "Transforming rather than transferring scientific and technological knowledge - the contribution of academic 'spin out' companies: the Italian way", in Oakey, R.P. and During, W.E. (Eds), New Technology-Based Firms in the 1990s, Vol. 5, Paul Chapman Publishing, London.

Cohen, B. and Winn, M.I. (2007), "Market imperfections, opportunity and sustainable entrepreneurship", Journal of Business Venturing, Vol. 22 No. 1, pp. 29-49.

Contigiani, A. and Levinthal, D.A. (2019), "Situating the construct of lean start-up: adjacent conversations and possible future directions", Industrial and Corporate Change, Vol. 28 No. 3, pp. 551-564.

Corbo, L. (2017), "In search of business model configurations that work: lessons from the hybridization of Air Berlin and JetBlue”, Journal of Air Transport Management, Vol. 64, pp. 139-150.

Corbo, L., Pirolo, L. and Rodrigues, V. (2018), "Business model adaptation in response to an exogenous shock: an empirical analysis of the Portuguese footwear industry", International Journal of Engineering Business Management, Vol. 10, pp. 1-12.

Do, E.Y.L., Gross, M.D., Neiman, B. and Zimring, C. (2000), "Intentions in and relations among design drawings", Design Studies, Vol. 21 No. 5, pp. 483-503.

Eisenmann, T.R., Ries, E. and Dillard, S. (2012), "Hypothesis-driven entrepreneurship: the lean startup", Harvard Business School Entrepreneurial Management Case, pp. 812-095.

Felin, T., Gambardella, A., Stern, S. and Zenger, T. (2019), "Lean startup and the business model: experimentation revisited", Long Range Planning, doi: 10.1016/j.lrp.2019.06.002.

Gherardi, S. and Nicolini, D. (2000), "To transfer is to transform: the circulation of safety knowledge", Organization, Vol. 7 No. 2, pp. 329-348.

Graham, I.D., Logan, J., Harrison, M.B., Straus, S.E., Tetroe, J., Caswell, W. and Robinson, N. (2006), "Lost in knowledge translation: time for a map?", Journal of Continuing Education in the Health Professions, Vol. 26 No. 1, pp. 13-24.

Hargadon, A.B. and Douglas, Y. (2001), "When innovations meet institutions: edison and the design of the electric light”, Administrative Science Quarterly, Vol. 46 No. 3, pp. 476-501.

Kim, S.K. and Min, S. (2015), "Business model innovation performance: when does adding a new business model benefit an incumbent?", Strategic Entrepreneurship Journal, Vol. 9 No. 1, pp. 34-57.

Kolb, D. (1984), Experiential Learning: Experience as the Source of Learning and Development, Prentice-Hall, New Jersey, NJ.

Krippendorff, K. (1989), "On the essential contexts of artifacts or on the proposition that design is making sense (of things)", Design Issues, Vol. 5 No. 2, pp. 9-39.

Krippendorff, K. (2006), Semantic Turn: New Foundations for Design, Taylor and Francis, Boca Raton, Florida, FL.

Landoni, P., Dell'era, C., Frattini, F., Petruzzelli, A.M. and Manelli, L. (2019), Business Model Innovation in Cultural and Creative Industries: Insights from Three Leading Mobile Gaming Firms, Technovation, doi: 10.1016/j.technovation.2019.102084. 
Levitt, B. and March, J.G. (1988), “Organizational learning”, Annual Review of Sociology, Vol. 14 No. 1, pp. 319-338.

Markides, C.C. (2008), Game-changing Strategies: How to Create New Market Space in Established Industries by Breaking the Rules, John Wiley \& Sons, New York, NY.

Maurya, A. (2012), Running Lean, 2nd ed., O'Reilly Media, Inc., Sebastopol, California, CA.

McGrath, R.G. (2010), "Business models: a discovery driven approach”, Long Range Planning, Vol. 43 Nos 2-3, pp. 247-261.

Osterwalder, A. (2004), The Business Model Ontology a Proposition in a Design Science Approach, Unpublished Manuscript, Université de Lausanne, Lausanne.

Osterwalder, A. and Pigneur, Y. (2010), Business Model Generation: A Handbook for Visionaries, Game Changers, and Challengers, John Wiley \& Sons, New York, NY.

Osterwalder, A., Pigneur, Y. and Tucci, C.L. (2005), "Clarifying business models: origins, present, and future of the concept", Communications of the Association for Information Systems, Vol. 16 No. 1, p. 1.

Pati, R.K., Nandakumar, M.K., Ghobadian, A., Ireland, R.D. and O'Regan, N. (2018), "Business model design-performance relationship under external and internal contingencies: evidence from SMEs in an emerging economy", Long Range Planning, Vol. 51 No. 5, pp. 750-769.

Picken, J.C. (2017), "From startup to scalable enterprise: laying the foundation", Business Horizons, Vol. 60 No. 5 , pp. 587-595.

Presenza, A. and Petruzzelli, A.M. (2019), "Investigating business model innovation in Haute Cuisine. Role and behavior of chef-entrepreneurs", International Journal of Hospitality Management, Vol. 82, pp. 101-111.

Rask, M. and Günzel-Jensen, F. (2019), "Business model design and performance in nascent markets", Management Decision, Vol. 58 No. 5, pp. 927-947.

Ries, E. (2009), "Minimum viable product: a guide", available at: http://www.startuplessonslearned. com/2009/08/minimum-viable-product-guide.html.

Ries, E. (2011), The Lean Startup: How Today's Entrepreneurs Use Continuous Innovation to Create Radically Successful Businesses, Crown Business, New York, NY.

Rohan, D. and Hornblower, J. (2008), "Identifying venture opportunities", Teaching Case E-323, Graduate School of Business, Stanford University.

Savory, C. (2006), "Translating knowledge to build technological competence", Management Decision, Vol. 44 No. 8, pp. 1052-1075.

Secundo, G., Del Vecchio, P., Simeone, L. and Schiuma, G. (2019), “Creativity and stakeholders' engagement in open innovation: design for knowledge translation in technology-intensive enterprises", Journal of Business Research, doi: 10.1016/j.jbusres.2019.02.072.

Shah, R. and Ward, P.T. (2003), "Lean manufacturing: context, practice bundles, and performance", Journal of Operations Management, Vol. 21 No. 2, pp. 129-149.

Shane, S.A. (2003), A General Theory of Entrepreneurship: The Individual-Opportunity Nexus, Edward Elgar Publishing, Cheltenham.

Simeone, L., Secundo, G. and Schiuma, G. (2017a), "Knowledge translation mechanisms in open innovation: the role of design in R\&D projects", Journal of Knowledge Management, Vol. 21 No. 6, pp. 1406-1429.

Simeone, L., Secundo, G. and Schiuma, G. (2017b), "Adopting a design approach to translate needs and interests of stakeholders in academic entrepreneurship: the MIT Senseable City Lab case", Technovation, Vol. 64, pp. 58-67.

Simeone, L., Secundo, G. and Schiuma, G. (2018), "Arts and design as translational mechanisms for academic entrepreneurship: the metaLAB at Harvard case study", Journal of Business Research, Vol. 85, pp. 434-443.
Continuous validation framework

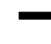


Singaram, M. and Jain, P. (2018), "What is the difference between proof of concept and prototype?", Entrepreneur, available at: https://www.entrepreneur.com/article/307454.

Sosna, M., Trevinyo-Rodríguez, R.N. and Velamuri, S.R. (2010), "Business model innovation through trial-and-error learning: the Naturhouse case", Long Range Planning, Vol. 43 Nos 2-3, pp. 383-407.

Sull, D.N. (2004), “Disciplined entrepreneurship”, MIT Sloan Management Review, Vol. 46 No. 1, p. 71.

Teece, D.J. (2010), “Business models, business strategy and innovation”, Long Range Planning, Vol. 43 Nos 2-3, pp. 172-194.

Wang, C.L. and Chugh, H. (2014), "Entrepreneurial learning: past research and future challenges", International Journal of Management Reviews, Vol. 16, pp. 24-61.

Wirtz, B.W., Pistoia, A., Ullrich, S. and Göttel, V. (2016), "Business models: origin, development and future research perspectives", Long Range Planning, Vol. 49 No. 1, pp. 36-54.

Zott, C. and Amit, R. (2008), "The fit between product market strategy and business model: implications for firm performance”, Strategic Management Journal, Vol. 29 No. 1, pp. 1-26.

Zott, C. and Amit, R. (2010), "Business model design: an activity system perspective", Long Range Planning, Vol. 43 Nos 2-3, pp. 216-226.

Ţurcan, R.V. (2008), "Entrepreneur-venture capitalist relationships: mitigating post-investment dyadic tensions", Venture Capital, Vol. 10 No. 3, pp. 281-304.

\section{About the authors}

Leonardo Corbo is Senior Assistant Professor of management at the University of Bologna, where he also obtained a $\mathrm{PhD}$ in business Administration. Before joining the University of Bologna, he was an assistant professor of management at Catolica Porto Business School. He has been a visiting scholar at Kellogg School of Management, Northwestern University and Sauder School of Business, University of British Columbia. His research interests include alliances and networks, business model innovation and new venture creation. His work has appeared in renowned international journals, including Organization Studies and the Journal of Air Transport Management. Leonardo Corbo is the corresponding author and can be contacted at: leonardo.corbo@unibo.it

Shadi Mahassel is a Co-founder and a CEO of SURFnCODE, a product studio that partners with hand-picked founders to create new products and scale teams into standalone businesses. Prior to that, he was VP Product at Veniam, responsible for building and managing Skype WiFi and a principal group program manager at Microsoft leading the development of Microsoft connectivity applications for consumers and enterprises. He has been a founder, advisor and investor in innovative technology companies in mobile communication media and e-commerce. He is active in the start-up community in Silicon Valley, London and Porto as an investor and advisor.

Alberto Ferraris, $\mathrm{PhD}$ in business and management, is currently working as a senior researcher at the University of Turin. He obtained the qualification of associate professor at the National Scientific Evaluation in Italy in 2017. Since 2016, he is a research fellow of the Laboratory for International and Regional Economics, Ural Federal University (Russia), and he is a fellow (F-EMAB) and an active member of the EuroMed Research Business Institute. He is an author of many academic and scientific articles as well as he serves as a guest editor or in the editorial board in several prestigious international journals, such as Journal of International Management.

For instructions on how to order reprints of this article, please visit our website:

www.emeraldgrouppublishing.com/licensing/reprints.htm

Or contact us for further details: permissions@emeraldinsight.com 